\title{
QUALIDADE DE CAQUIS FUYU TRATADOS COM CÁLCIO EM PRÉ-COLHEITA E ARMAZENADOS SOB ATMOSFERA MODIFICADA ${ }^{1}$
}

\author{
VALDECIR CARLOS FERRI ${ }^{2}$, MARIA MADALENA RINALDI ${ }^{3}$, \\ LUCIANO LUCHETTA $^{4}$, CESAR VALMOR ROMBALDI $^{5}$
}

\begin{abstract}
RESUMO - Avaliou-se a eficiência do cálcio $\left(\mathrm{CaCl}_{2}\right)$ na conservação de caquis $F$ uyu armazenados em temperatura ambiente (TA), atmosfera refrigerada (AR) e modificada (AM). Utilizou-se um delineamento inteiramente casualizado, com quatro repetições. Os caquizeiros foram tratados com $1 \%$ de $\mathrm{CaCl}_{2}$, em pulverizações de cobertura total, a cada 15 dias, a partir de 90 dias antes da data prevista para a colheita. Para a testemunha, pulverizaram-se as plantas com água destilada. As frutas foram colhidas com 65-75mm de diâmetro, coloração verde-amarelada e armazenadas em: 1 - TA $\left(23 \pm 3^{\circ} \mathrm{Ce} 75 \pm 5 \%\right) ; 2$ - $\mathrm{AR}\left(0 \pm 0,5^{\circ} \mathrm{Ce} 90 \pm 5 \%\right.$ de umidade relativa); e 3 AM (filme de polietileno de baixa densidade $33 \mu \mathrm{m}, 29 \times 46 \mathrm{~cm}, 0 \pm 0,5^{\circ} \mathrm{C}$ e umidade relativa $90 \pm 5 \%$ ), durante 80 dias. As frutas foram submetidas a avaliações de perda de peso, firmeza de polpa, sólidos solúveis totais e escurecimento da epiderme. As avaliações foram efetuadas 24 e 96 horas após as frutas serem retiradas da câmara. Para as frutas armazenadas em TA, as análises foram realizadas a cada 4 dias, durante 20 dias. A aplicação de $\mathrm{CaCl}_{2}$ em pré-colheita melhorou o potencial de armazenamento, e a AM teve efeito sinérgico ao $\mathrm{CaCl}_{2}$ na melhoria do potencial de conservação dos caquis.
\end{abstract}

Termos de indexação: pós-colheita, etileno, maturação, armazenamento

\section{QUALITY OF FUYU KAKIS TREATED WITH CALCIUM BEFORE THE HARVEST AND STORAGED IN CONDITION OF MODIFIED ATMOSPHERE}

\begin{abstract}
The present work aimed to evaluate the efficiency of calcium $\left(\mathrm{CaCl}_{2}\right)$, in the conservation of Fuyu kakis stored in: ambient temperature (AT), refrigerated atmosphere (RA) and modified atmosphere (MA). It was used randomized method as a design with four replications. The kakis were treated with $1 \% \mathrm{CaCl}_{2}$ applied to the plants 90 days before the harvest every 15 days, in the form of total cover sprays. It was used distillated water as control treatment. The fruits were picked (1997/98) with a diameter of 65-75mm, green-yellow coloring and stored in: 1 - AT $\left(23 \pm 3^{\circ} \mathrm{C}\right.$ and $75 \pm 5 \%$ of relative humidity); 2 - RA (temperature of $0 \pm 0.5^{\circ} \mathrm{C}$ and $90 \pm 5 \%$ of relative humidity) and 3 - MA (low-density polyethylene film $33 \mu \mathrm{m}, 29 \times 46 \mathrm{~cm}$, kept at temperatures of $0 \pm 0.5^{\circ} \mathrm{C}$ and relative humidity of $90 \pm 5 \%$ ) during 80 days. The fruits were submitted to evaluations of weight loss, pulp firmness, total soluble solids and external breakdown. The evaluations were performed 24 and 96 hours after the removal from the cold storage. The results indicate that the application of $\mathrm{CaCl}_{2}$ before the harvest increased the storage potential of the fruits. The usage of MA showed synergic effect, contributing to the potential improvement of kakis conservation.
\end{abstract}

Index terms: post-harvest, ethylene, ripening, storage

\section{INTRODUÇÃO}

O caquizeiro (Diospyrus kaki L.) foi introduzido no Brasil no início do século XX por imigrantes japoneses. Entretanto, a expansão dessa cultura só ocorreu a partir de 1970, com maior expressão na Região Sudeste. Na década de 90, a área cultivada com esta espécie praticamente dobrou, porém a demanda de mercado não acompanhou esse incremento. Isto gera a necessidade de se estabelecer condições de manejo na pré-colheita, na colheita e no armazenamento para ampliar o período de colheita e de armazenamento dessa fruta.

O Fuуи é promissora em termos de mercado, pois produz frutas grandes (150 a 200g), de polpa amarelo-avermelhada não adstringente, sem sementes e com coloração da epiderme que varia de amarelo-esverdeada a avermelhada. Entretanto, dois problemas essenciais ainda limitam a harmonização da cadeia produtiva: i) o abortamento floral; ii) o curto período de conservação da fruta.

De acordo com Kader et al. (1989), as ações para a solução desses pontos de estrangulamento devem ser adotadas na pré e na pós-colheita, posto que a velocidade e a intensidade com que as alterações fisiológicas ocorrem nas frutas, são dependentes das características genotípicas (Abeles et al., 1992), das condições edafoclimáticas e de cultivo (Kader et al., 1989), colheita e armazenamento (Brackman \& Saquet, 1995). A maioria das ações implementadas, visando a prolongar o período de conservação das frutas in natura, estão baseadas na redução da atividade metabólica e de organismos associados ao produto.

1 (Trabalho 074/2001). Recebido: 27/03/2001. Aceito para publicação: 03/06/2002.

2 Eng $^{\circ}$ Agro $^{\circ}$, Msc. Doutorando em Fruticultura de Clima Temperado da UFPel/FAEM.

3 Eng ${ }^{\circ}$ Agr $^{\circ}$, Msc. em Ciência e Tecnologia Agroindustrial da UFPel/FAEM.

4 Acadêmico de Agronomia da UFPel/FAEM, Bolsista PBIC-CNPq.

5 Engo Agró, Dr. Prof. Adjunto do Dep. de Ciência e Tecnologia Agroindustrial da UFPel/FAEM, Cx. P. 354, 96.010-900 Pelotas RS. E-mail: cesarvf@ufpel.tche.br 
As pulverizações com cálcio, durante as fases de préfloração, floração e crescimento das frutas, têm sido recomendadas como forma de reduzir os índices de abortamento floral, os distúrbios fisiológicos pós-colheita, a taxa respiratória, a produção de etileno e de preservar a firmeza da polpa (Perez et al., 1995).

Scalon et al. (1996) atribuem ao cálcio a capacidade de retardar os processos de amadurecimento e senescência das frutas, ao diminuir a taxa respiratória e a produção de etileno, controlar distúrbios fisiológicos, manter a integridade e funcionalidade das membranas celulares, além de manter a firmeza da fruta ao formar ligações entre pectinas ácidas da parede celular e lamela média (Poovaiah, 1986 e Glenn et al., 1988). Vários trabalhos (Perez et al., 1995; Brackmann \& Saquet, 1995; Brackmann et al., 1997 e Ferri et al., 1999) vêm sendo desenvolvidos na tentativa de verificar a eficiência do cálcio na redução da incidência de podridões e no prolongamento de armazenamento, especialmente em maçãs (Brackmann et al., 1997).

Dentro deste contexto, o objetivo deste trabalho foi monitorar o efeito do cálcio aplicado em pré-colheita, em caquis Fuyu, no potencial de armazenamento desta cultivar em atmosfera refrigerada, refrigerada modificada e em temperatura ambiente.

\section{MATERIAL E MÉTODOS}

Os tratamentos (safra 1997/98) foram desenvolvidos em propriedade localizada no município de Canguçu - RS. Os caquizeiros $F u y u$, de 11 anos de idade, foram tratados com $1 \%$ de cálcio $\left(\mathrm{CaCl}_{2}\right)$, em pulverizações de cobertura total, a cada 15 dias, a partir de 90 dias antes da data prevista para a colheita. Para a testemunha, aplicou-se água destilada na pulverização.

Os caquis foram colhidos, padronizados em tamanho e coloração da epiderme e pré-resfriados a $4^{\circ} \mathrm{C}$, por 24 horas.

$\mathrm{O}$ armazenamento foi feito em temperatura ambiente (TA), realizado a $23 \pm 3^{\circ} \mathrm{Ce} 75 \pm 5 \%$ de umidade relativa; em atmosfera refrigerada $(A R)$ a $0 \pm 0,5^{\circ} \mathrm{C}$ e $90 \pm 5 \%$ de umidade relativa; $\mathrm{e}$ em atmosfera modificada (AM), com as frutas embaladas em filme de polietileno de baixa densidade (PEBD 35/55cm), 33 $\mu \mathrm{m}$ de espessura, e armazenadas a $0 \pm 0,5^{\circ} \mathrm{C}$ e $90 \pm 5 \%$ de umidade relativa. As análises fisiológicas, físicas e químicas foram realizadas a cada 96 horas para as frutas mantidas em TA, durante 20 dias, e para os demais tratamentos a cada 20 dias (acrescidos de 24 e 96 horas em comercialização simulada a $23 \pm 3^{\circ} \mathrm{C}$ e $75 \pm 5 \%$ de umidade relativa), durante 80 dias.

O delineamento experimental adotado foi completamente casualizado, com pulverizações de quatro plantas, constituindo as repetições a campo. Na etapa de pós-colheita, as frutas foram acondicionadas em bandejas plásticas de 12 frutas, constituindo as unidades experimentais. Seguiu-se o esquema fatorial
$2 \times 3 \times 5 \times 2$ (pulverizações a campo $\mathrm{x}$ sistemas de armazenamento $\mathrm{x}$ períodos de armazenamento x período após a retirada da câmara fria).

Determinou-se a firmeza de polpa com penetrômetro manual de ponteira $8 \mathrm{~mm}$ em duas determinações após a remoção da casca, em faces opostas, localizadas na zona equatorial das frutas, expressando os resultados em Newton (N); os Sólidos Solúveis Totais (SST) foram medidos em refratômetro manual e os resultados expressos em ${ }^{\circ}$ Brix; a produção de etileno foi medida por cromatografia em fase gasosa e expressa em nL.h ${ }^{-1} \cdot \mathrm{g}^{-1} ; \mathrm{o}$ cálcio foi quantificado por digestão a quente dos frutos com leituras em espectrofotômetro de chamas e os resultados expressos em mg. $\mathrm{kg}^{-1}$; a ocorrência de escurecimento de epiderme (EE) e/ou podridões na epiderme, através de notas atribuídas em escala: (1) frutos sadios; (2) 30\% de danos; (3) $60 \%$ de danos; e (4) $90 \%$ de danos, com limites máximos aceitáveis até a escala 2.

Os dados resultantes foram submetidos à análise de variância e as médias comparadas pelo teste de Duncan, a 5\% de probabilidade.

\section{RESULTADOS E DISCUSSÃO}

Os caquis provenientes de plantas tratadas e não tratadas com cálcio não apresentaram variações significativas na firmeza de polpa, conteúdos de SST e de cálcio (Tabela 1) no dia da colheita.

Quando essas frutas foram armazenadas durante 20 dias, o tratamento com cálcio e o sistema de armazenamento afetaramnas significativamente (Tabela 2), especialmente na firmeza de polpa e ocorrência de escurecimento da epiderme. Os caquis tratados com cálcio mantiveram maiores valores de firmeza de polpa e menor incidência de escurecimento. Verificou-se um efeito significativo da AM na preservação dessas características.

Ao analisar-se as frutas 96 horas após a retirada da câmara fria, os efeitos do cálcio e da AM foram mais evidentes (Tabela 2). Para que os caquis $F u y u$ tenham boa aceitação no mercado consumidor, segundo Mitcham et al. (1998), a firmeza de polpa deve estar entre 20 e $60 \mathrm{~N}$.

Todas as frutas tratadas com cálcio apresentavam firmeza de polpa superior a 20N e baixa ocorrência de escurecimento da epiderme. Já, em frutas não tratadas e armazenadas em TA e $\mathrm{AR}$, houve uma significativa alta na ocorrência de escurecimento. Verificou-se o efeito benéfico do cálcio na preservação da firmeza de polpa, tanto as frutas mantidas em TA, AR quanto em AM, após 96 horas.

Os resultados de SST (Tabela 2), 24 horas após as frutas serem retirada da câmara fria, não diferiram estatisticamente entre si, independentemente do uso de cálcio ou não. Esses valores são semelhantes aos relatados para a maioria das regi-

TABELA 1 - Características de caquis Fuyu, de plantas tratadas (c/Ca) e não tratadas (s/Ca) com CaCl 2 (1\%). Canguçu-RS, 22-03-1998.

\begin{tabular}{|c|c|c|}
\hline \multirow[t]{2}{*}{ Características } & \multicolumn{2}{|c|}{ Tratamentos } \\
\hline & $\mathrm{s} / \mathrm{C} \mathrm{a}$ & $\mathrm{c} / \mathrm{C} \mathrm{a}$ \\
\hline Firmeza de polpa (N) & $69 \mathrm{a}$ & $71 \mathrm{a}$ \\
\hline $\operatorname{SST}\left({ }^{\circ} \mathrm{B}\right.$ rix $)$ & $17 \mathrm{a}$ & $16,5 \mathrm{a}$ \\
\hline Concentração de cálcio $\left(\mathrm{mg}_{\mathrm{g}} \mathrm{kg}^{-1}\right)$ & 0,09 a & $0,07 \mathrm{a}$ \\
\hline
\end{tabular}

* Médias com letras diferentes na mesma linha indicam variação significativa com 5\% de probabilidade, pelo teste de Duncan. 
TABELA 2 - Características de caquis $F u y u$, de plantas tratadas (c/Ca) e não tratadas (s/Ca) com $\mathrm{CaCl}_{2}(1 \%$ ) e armazenados por 20 dias em temperatura ambiente (TA) e sob refrigeração. As análises foram realizadas após 24 e 96 horas da retirada da câmara fria. Canguçu-RS, 11-04-1998.

\begin{tabular}{|c|c|c|c|c|c|c|c|}
\hline \multirow{3}{*}{ 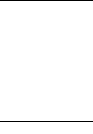 } & \multirow{3}{*}{ Características } & \multicolumn{6}{|c|}{ Tratamentos } \\
\hline & & \multicolumn{3}{|c|}{$\mathrm{s} / \mathrm{C} \mathrm{a}$} & \multicolumn{3}{|c|}{$\mathrm{c} / \mathrm{C} \mathrm{a}$} \\
\hline & & $\mathrm{TA}$ & A R & A M & $\mathrm{TA}$ & A R & A M \\
\hline \multirow{4}{*}{$24 \mathrm{~h}$} & Firm eza de polpa (N) & $18 \mathrm{~d}$ & $56 \mathrm{~b}$ & $65 \mathrm{a}$ & $26 \mathrm{c}$ & $66 \mathrm{a}$ & $65 \mathrm{a}$ \\
\hline & $\operatorname{SST}\left({ }^{\circ} \mathrm{B} \mathrm{rix}\right)$ & 16,5 a & $16 \mathrm{a}$ & $16 \mathrm{a}$ & $16 \mathrm{a}$ & 16,5 a & 16,5 a \\
\hline & cálcio $\left(\mathrm{mg} \cdot \mathrm{kg}^{-1}\right)$ & 0,07 a & 0,08 a & $0,07 \mathrm{a}$ & 0,09 a & $0,07 \mathrm{a}$ & 0,08 a \\
\hline & $\operatorname{EE}($ nota $)$ & $2 \mathrm{a}$ & $1 \mathrm{~b}$ & $1 \mathrm{~b}$ & $1 \mathrm{~b}$ & $1 \mathrm{~b}$ & $1 \mathrm{~b}$ \\
\hline \multirow{3}{*}{$96 \mathrm{~h}$} & Firm eza de polpa (N) & $18 \mathrm{~d}$ & $50 \mathrm{c}$ & $61 \mathrm{a}$ & $23 \mathrm{~d}$ & 63 a & $64 \mathrm{a}$ \\
\hline & $\operatorname{SST}\left({ }^{\circ} \mathrm{B} \mathrm{rix}\right)$ & 16,7 a & $16 \mathrm{a}$ & $16 \mathrm{a}$ & $16 \mathrm{a}$ & $17 \mathrm{a}$ & $17 \mathrm{a}$ \\
\hline & E E (nota) & $3 \mathrm{a}$ & $2 \mathrm{~b}$ & $1 \mathrm{c}$ & $1 \mathrm{c}$ & $1 \mathrm{c}$ & $1 \mathrm{c}$ \\
\hline
\end{tabular}

- Médias com letras diferentes na mesma linha indicam variação significativa com 5\% de probabilidade, pelo teste de Duncan.

ões e países onde esta cultura é pesquisada (Hirai \& Yamazaki, 1984; Sargent et al., 1993; Collins \& Tisdell, 1994 e Brackmann \& Saquet, 1995).

Entretanto, após 96 horas (Tabela 2), as frutas tratadas com cálcio apresentaram teores de SST superiores aos das não tratadas.

Os resultados de SST são, em parte, concordantes com alguns autores (Ben-Arie et al., 1986; Sargent et al., 1993 e Collins \& Tisdell, 1995), que relatam uma tendência de ligeira redução de SST em caquis armazenados. Entretanto, para Hirai \& Yamazaki (1984), Senter et al.(1991) e Maness et al. (1992), os teores de SST, nos primeiros dias após a colheita, tendem a aumentar, seguidos de redução. Para Moura et al. (1997), o conteúdo de SST em caquis é crescente durante o armazenamento. Porém, segundo Rinaldi et al.(1998), pode-se também verificar redução dos SSTs seguida de posteriores acréscimos.

Aplicações de cálcio proporcionam condições capazes de reduzir o metabolismo das frutas sem causar distúrbios de escurecimento da epiderme, ao menos até 20 dias de armazenamento refrigerado, seguido de 24 horas à temperatura ambiente (Tabela 2). Estes mesmos resultados revelam também o efeito que o uso de AM exerce sobre o controle do escurecimento da epiderme dos caquis.

Após 80 dias de armazenamento, observou-se efeito significativo da aplicação de cálcio e do uso de AM (Tabela 3). Em frutas armazenadas em AR, houve perda total de firmeza de polpa, enquanto, em AM, a firmeza observada foi de $5 \mathrm{~N}$ e $22 \mathrm{~N}$, respectivamente, para frutas não tratadas e tratadas com cálcio. Os conteúdos de SST e de cálcio não apresentaram variações significativas.

Em caquis mantidos 96 horas em condições de comercialização simulada, após 80 dias (Tabela 3), somente aqueles tratados com cálcio e armazenados em AM mantiveram condições de consumo, com razoável firmeza de polpa e menor ocorrência de escurecimento da epiderme.

De maneira geral, os resultados mostram o efeito positivo do cálcio na manutenção da qualidade de caquis. Entretanto, a aplicação de cálcio não proporcionou incremento deste cátion nas frutas. Este comportamento também foi observado em pêssegos (Mitchell \& Crisosto, 1998). Em maçãs, onde a maioria dos trabalhos com cálcio têm sido realizados, os resultados são controvertidos. Segundo Liv (1998), devido à baixa absorção e translocação do cálcio, e dependendo da espécie e condições climáticas, as aplicações em pulverizações de cobertura nem sempre induzem a um aumento da concentração deste cátion. Às vezes, há um aumento localizado, apenas na região da epiderme. Este comportamento ocorre principalmente em frutas com elevada taxa de crescimento na fase inicial do amadurecimento, como é o caso de pêssegos. Também ocorre em regiões de alta pluviosidade. Isto pode explicar o comportamento observado nos caquis que, em média, triplicaram de peso nos últimos 30 dias que antecederam a colheita (dados não apresentados).

Além destas constatações, verificou-se que os caquis tratados com cálcio apresentaram melhor aparência externa, não somente pela menor ocorrência de escurecimento, mas também pela sua coloração mais uniforme e brilhante (dados não apresentados).

TABELA 3 - Características de caquis Fuyu, de plantas tratadas (c/Ca) e não tratadas (s/Ca) com $\mathrm{CaCl}_{2}$ (1\%) e armazenadas por 80 dias em temperatura ambiente (TA) e sob refrigeração. As análises foram realizadas após 24 e 96 horas da retirada da câmara fria. Canguçu-RS, 12-06-1998.

\begin{tabular}{|c|c|c|c|c|c|}
\hline & \multirow{3}{*}{ C aracterísticas } & \multicolumn{4}{|c|}{ Tratamentos } \\
\hline & & \multicolumn{2}{|c|}{$\mathrm{s} / \mathrm{C} \mathrm{a}$} & \multicolumn{2}{|c|}{$\mathrm{c} / \mathrm{C} \mathrm{a}$} \\
\hline & & A R & A M & A R & $\mathrm{A} \mathrm{M}$ \\
\hline \multirow{4}{*}{$24 \mathrm{~h}$} & Firmeza de polpa (N) & 000 & $5 \mathrm{~b}$ & $000 \mathrm{c}$ & $22 \mathrm{a}$ \\
\hline & S S T $\left({ }^{\circ} \mathrm{B} \mathrm{rix}\right)$ & 16,6 a & 16,2 a & 16,3 a & $16 \mathrm{a}$ \\
\hline & Cálcio $\left(\mathrm{mg} \mathrm{kg}^{-1}\right)$ & $0,06 \mathrm{a}$ & $0,06 \mathrm{a}$ & $0,08 \mathrm{a}$ & $0,07 \mathrm{a}$ \\
\hline & $\mathrm{EE}(\mathrm{nota})$ & $4 \mathrm{a}$ & $2 \mathrm{c}$ & $3 \mathrm{~b}$ & $2 \mathrm{c}$ \\
\hline \multirow{3}{*}{$96 \mathrm{~h}$} & Firmeza de polpa (N) & $00 \mathrm{c}$ & $3 \mathrm{~b}$ & $00 \mathrm{c}$ & $7 \mathrm{a}$ \\
\hline & S S T $\left({ }^{\circ} \mathrm{B} \mathrm{rix}\right){ }^{1}$ & $\mathrm{nd}$ & 17,3 a & $\mathrm{nd}$ & $16,1 \mathrm{a}$ \\
\hline & $\mathrm{EE}(\mathrm{nota})$ & $4 \mathrm{a}$ & $4 \mathrm{a}$ & $4 \mathrm{a}$ & $3 \mathrm{~b}$ \\
\hline
\end{tabular}

Médias com letras distintas na mesma linha indicam variação significativa com $5 \%$ de probabilidade, pelo teste de Duncan.

nd = valores não determinados. 


\section{CONCLUSÃO}

1 - A aplicação quinzenal de cálcio, a partir de 90 dias antes da data prevista para a colheita, na forma de $\mathrm{CaCl}_{2}$ a $1 \%$, em pulverização de cobertura de plantas, melhora o potencial de conservação de caquis Fuyu.

2 - A associação de cálcio com o armazenamento em atmosfera modificada amplia o período seguro de conservação de caquis Fuyu.

\section{REFERÊNCIAS BIBLIIOGRÁFICAS}

ABELES, F.B.; MORGAN, P.W.; SALTVEIT, M.E. Ethylene in plant biology. $2^{\text {nd }} . e d$. San Diego. 1992. 414p.

BEN-ARIE, R.; BAZAK, H.; BLUMENFELD, A. Gibberellin delays harvest and prolongs life of persimmon fruits. Acta Horticulturae, Wageningen, v.179, p.807-813. 1986.

BRACKMANN, A.; SAQUET, A.A. Efeito da temperatura e condições de atmosfera controlada sobre a conservação de caqui. Ciência Rural, Santa Maria, v.25, n.3, p.375-378, 1995.

BRACKMANN, A.; MAZARO, S.M.; SAQUET, A.A. Frigoconservação de caquis (Diospyros kaki, L.) das cultivares fuyu e rama forte. Ciência Rural, Santa Maria, v.27, n.4, p.561$565,1997$.

COLLINS, R. J.; TISDELL, J. S. 1995. The influence of storange time and temperature on chilling injury in Fuyu and Suruga persimmon (Diospyrus kaki, L.) grow in subtropical Austrália. Postharvest Biology and Tecnology, Amsterdam, v.6, p.149-157, 1995.

FERRI, V.C.; DANIELI, R.; LUCCHETTA, L.; LEITZKE, W.; ROMBALDI, C.V. Aplicação de cálcio na conservabilidade de caquis (Diospyros kaki, L.), cultivar Fuyu. In: ENCONTRO REGIONAL SUL DECTA, 6., 1999. Curitiba.p.76.

HIRAI, S.; YAMAZAKI, K. 1984. Studies on sugar components os sweet and astringent persimmon by gas chromatography. Journal of Japanese Society of Food Science Technology,n.31, p.24-30, 1984.

GLENN, G.M.; REDDY, A.S.N.; POOVAIAH, B.W. Effect of calcium cell wall structure protein phodphorilation and protein profile in senecing apples. Plant Cell Phisiology, v.29, n.4, p.565572,1988 .

KADER, A.A.;ZAGORY, D.; KERBEL, E.L. 1989. Modified atmosphere pakaging of fruits and vegetables. Critical Reviews in
Food Science and Nutritin, Boca Raton, v.28, n.1. p.1-30, 1989.

LIV, S.A. Effects of calcium in ripening climacteric fruits. Fruits Technology. V.25, n.3, p.1104-1109, 1998.

MANESS, N.O.;BRUSEWITZ, G.H.; MCCOLLUM, T.G.Internal variation in peach fruit firmness. Hortscience, Alexandria, v.27, n.8, p.903-905, 1992.

MITCHAM, J.E.; CRISOSTO, C.H.; KADER, A.A. Recommendations for maintaining postharvest quality. Davis, Department of Pomology, University of California, 1998. 120 p.

MITCHELL, A.; CRISOSTO, F.F. Calcium in peach fruits. Horticultural Science. Stuttgart, n.14, p.2125-2128, 1998.

MOURA, M. A.; LOPES, L. C.; CARDOSO, A.A.; MIRANDA, L. C. G. 1997. Efeito da embalagem e do armazenamento no amadurecimento do caqui. Revista Pesquisa Agropecuária Brasileira, Brasília, v.32, n.11, p.1105-1109, 1997.

PEREZ, A.; BEN-ARIE, R.; DINNOR, A.; GENIZI, A.; PRUSKY, $D$. Prevention of black spot disease in persimmon fruit by gibberellic acid and iprodione treatments. Phytopathology, St. Paul, v.85, n.2, p.221-225, 1995.

POOVAIAH, B.W. Role of calcium in prolonging storage life of fruyt and vegetables. Food Technology, Chicago. v.16, p.86-89, 1986.

RINALDI, M.M.; FERRI, V.C.; ROMBALDI, C.V. Frigoconservação de caquis (Diospyros kaki, L.) cv. Fuyu, em atmosfera modificada. In: CONGRESSO BRASILEIRO DE CIÊNCIA E TECNOLOGIA DE ALIMENTOS, 16, 1998, Rio de Janeiro, RJ. Anais... Rio de Janeiro: S.B.C.T.A. - Universidade Federal do Rio de Janeiro. v.2, p.415-420.

SARGENT, S. A.; CROCKER, T. E.; ZOELLNER, J. J. Storage characteristics of Fuyu persimmons. Proceedings Fla. State Horticulturae Society, Florida, n.106, p.131-134, 1993.

SCALON, S.P.Q.; BITTENCOURT, A.L.; CHITARRA, A.B.; CHITARRA, M.I.F. 1996. A evolução da qualidade e da vida útil de morangos (Fragraria ananassa, Duch.) submetidos à aplicação pós-colheita de $\mathrm{CaCl}_{2}$ armazenados sob atmosfera modificada e à temperatura ambiente. Ciência e Tecnologia de Alimentos, Campinas. v.16, n.1, p.83-87.

SENTER, S.D.; CHAPMAN, G.W.; FORBUS, W.R.; PAYNE, J.A. Sugar and non-volatile acid composition of persimmons during maturation. Journal of Food Science, Chicago, n.56, p.989-991, 1991. 